\title{
PSYCHE
}

VOL. XXXV.

DECEMBER 1928

No. 4

\section{MICROTRIMERIA COCKERELLI, A NEW GENUS AND SPECIES OF SOUTH AMERICAN MASARIDS (HYMENOPTERA)}

By J. BequaERT, Department of Tropical Medicine, Harvard University Medical School, Boston, Mass.

The wasp to be described in the present paper presents a number of features of more than usual interest. It not only adds one more species to the very small number of Masaridinæ known from the Neotropical Region; but it also extends the range of this subfamily of wasps to entirely new territory. Moreover, it differs in so many respects from the described members of the group, that it represents a distinct natural division, which I believe is of equal rank with the several genera that are at present, recognized in this subfamily.

Microtrimeria, new genus.

Finely sculptured species. Eye with a deep, triangular sinus. Clypeus shallowly emarginate at apex. Mouthparts apparently as in Trimeria, in so far as they can be seen without dissection: labrum short; labial palpi of 3 long segments; maxillary palpi rudimentary or absent. Antenna (in female) of 12 distinct segments; flagellum uniformly fusiform throughout, the apical segments not set off as a club. Parapsidal furrows present, complete. Tegula elongate, its posterior lobe reaching the base of the scutellum. Scutellum with a median, raised portion and a lateral, depressed rim, completely covering the postscutellum when seen from above. Posterior surface of propodeum vertical; its lateral angles broadly rounded, not mucronate. Middle 
tibia with two apical spurs; larger posterior tibial spur trifid at apex. Tarsal claws simple. Abdomen sessile; tergites not conspicuously divided into a basal, constricted and an apical, wider portion. Forewing not plaited; venation as in Trimeria.

Genotype: Microtrimeria cockerelli, new species.

Microtrimeria cockerelli, new species (Fig. 1).

A small, minutely sculptured species; black, with numerous ivory-white markings and slightly amber-yellow wings; fascix of the abdomen deeply bisinuate.

Total length: 우 , $7.5 \mathrm{~mm}$.; of wing, $5 \mathrm{~mm}$.

Female.- - Head broadly elliptical in front view, about one and one-fifth times as wide as high; seen from above, a little less than twice as wide as long, not broader than the thorax; occipital margin almost straight. Vertex and cheeks margined throughout by a sharp, even carina. Cheeks wide and distinctly swollen in their upper half, where they are still much narrower than the upper part of the eye in profile and are not in the least angular; gradually narrowed in their lower half, which is not

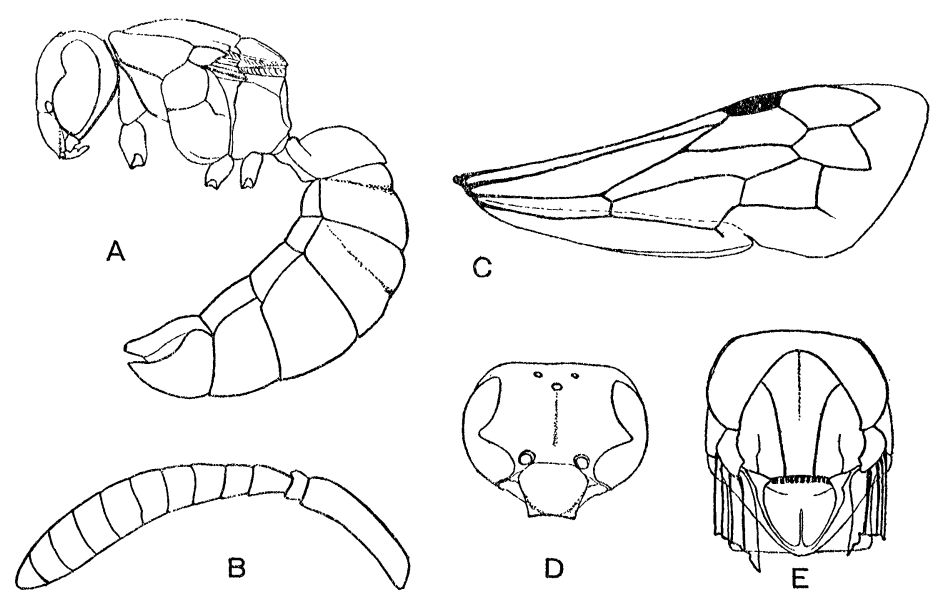

Fig. 1. Microtrimeria cockerelli T. Bequaert. Female: A, body in profile B. antenna; C; fore wing; $D$, head in front view; $E$, thorax from above. 
depressed; the marginal carina broadly and evenly rounded, not forming an angle. Inner orbits about one and one-third times as far apart on the vertex as at the clypeus. Front hardly swollen, with a slight longitudinal median groove over its upper two-thirds, beginning at the anterior ocellus. Ocelli large, in a flattened triangle; the posterior pair a little nearer to each other than to the inner orbits, about twice as far apart as they are from the anterior ocellus and about equally distant from the occipital margin as from the inner orbits. Interocellar area flat. Vertex not swollen, without fovea. Antonn: about five times as far apart as they are from the inner orbits; the area between them flat, without ridge, carina or depression. Clypeus irregularly hexagonal, with longer upper and lower margins, but little wider than long, very slightly convex in the middle, flattened toward the base, moderately depressed on the sides in its apical third, but without lateral grooves; the anterior, free portion a little longer than the basal, interocular part; the upper margin straight; the lateral margins forming rounded angles which are far removed from the inner orbits; the truncate apex about three-quarters of the maximum width of the clypeus, margined by a narrow, thickened rim, with a slight inward curve, forming right angles with the lateral margins; the lateral angles blunt, flat; owing to the sides of the clypeus being depressed at the apex, the apical margin appears triangularly emarginate when the head is seen from below. Antenna short, of twelve segments; the flagellum much swollen, gradually incrassate from the base to about the middle; scape almost uniformly swollen throughout, nearly half the length of the flagellum; second segment small; third segment about twice as long as the second, about one and one-third times as long as wide at the apex; the fourth a little over half the length of the third, wider than long; the fifth to eleventh much wider than long; the twelfth about as long as wide, bluntly rounded at apex; all the segments perfectly normal. Mandibles of the knife-like type, somewhat decussate, much shorter than the length of the eye, stout and but little curved; the apex forming a blunt, broadly rounded tooth; the inner margin with two shallow notches separating low, blunt teeth; the notches being the ends of two deep grooves which run over 
the outer surface of the mandible to near its base. Thorax rectangular, stubby, slightly narrowed anteriorly and a little more posteriorly; about one and one-fifth times as long as its greatest width and about as high as wide. Anterior margin of pronotum with a very slight outward curve, rounded off, without carina or rim; the humeral angle not projecting, broadly rounded; the lateral margin broadly curved and with a fine, sharp carina extending from the humeral angle to the mesopleuron and forming the upper border of the epienemia for the front legs. Mesonotum but little longer than wide, pentagonal in outline with the anterior third produced and the anterior angle semicircularly rounded; very slightly and uniformly convex; with deep, continuous parapsidal furrows and a finer, incomplete furrow on each side in the posterior third and parallel with the tegulæ; a fine median impressed line in the anterior half. Tegulæ much longer than wide, narrowed posteriorly, reaching the base of the scutellum on the sides; post-tegulæ not developed. Scutellum very large, broadly triangular, completely covering the postscutellum, which is hidden when looked at from above, with a median, raised portion, the margin of which is thickened and connected at the apex with a slight, median, longitudinal ridge which runs over the apical two-thirds; on each side of this median ridge the surface of the scutellum is flattened, but not distinctly grooved; the base is deeply depressed and the mesonotal suture bears a number of foveolæ; the marginal area of the scutellum forms an abruptly depressed, flat plate, which is broad on the sides and narrows gradually toward the apex, where it is but indistinctly divided from the median, raised area. Postscutellum very short, transversely elliptical, not visible from above; its surface vertical and in a plane with the concavity of the propodeum. Mesepisternum divided from the epimeron and with a complete suture separating the upper from the lower plate; anterior and posterior areas of the mesopleura abruptly constricted to form the edges of deep epicnemia for the front and middle legs; these depressions, however, not bordered by sharp prepectal carinæ (as in the case in Trimeria buyssoni); no prepectal suture is present, but the impressed line which marks the sternopleural suture is well marked. Propodeum short, squarely 
and vertically truncate behind, not swollen on the sides; dorsal areas broadly separated from each other by the postscutellum; concavity wide and shallowly depressed, with a fine, longitudinal median earina which runs from the postscutellum to the much thickened lower (apical) margin; superior, lateral and inferior ridges broadly rounded; lateral angles not produced, rounded; ventral areas fused with the metapleura. Lateral scales of the articulation of the abdomen narrow, broadly rounded. Abdomen moderately elongate, of almost normal shape, the several segments not conspicuously constricted basally. First tergite transverse, as wide as the second, broadly rounded in profile and not angular between the anterior, sloping part and the posterior, horizontal area; the horizontal portion about three times as wide as long. Second and third tergites with a slightly depressed, transverse line (or constriction) in or before the middle, more pronounced on the second tergite; last tergite normally convex; all the sternites normal, the apical one convex throughout, with a deep, narrow notch at apex; apex of first to fifth tergites with a narrow, translucent margin, which, however, is not raised nor set off by puncturation. Legs moderately stout, of normal shape; middle femora and tibiæ not appreciably swollen nor flattened; all coxæ and trochanters unarmed and of normal shape; front tarsi of normal shape, slender; anterior tibial spur strongly curved, slender, acute; middle tibia with two spurs of unequal length; larger posterior spur trifid at apex; tarsal claws simple. Wings with the venation of Trimeria: two closed submarginal cells; the medio-cubital cross-vein $(m-c u)$ attached basad of the submedian vein $(M 4+C u)$; radial cell very broad, not appendiculate; forewing not plaited; posterior lobe of hind wing well developed.

Body entirely covered with dense, microscopic puncturation (not visible with a hand lens); in addition with scattered fine punctures, which become larger, deeper and denser on the thorax and still coarser over the raised portion of the scutellum; the depressed apical margin of the scutellum with fine longitudinal striæ. The puncturation is still distinct on the first tergite, but becomes very faint and sparse on the succeeding tergites and on the sternites. Apical half of the clypeus granular. Head and 
thorax dull, the abdomen a little more shiny. Pilosity very sparse and short, grayish.

Black. Apical half of the mandibles, inner side of the front femora, inner side of all tibiæ, tibial spurs, tarsi, center of tegulæ, and extreme apex of abdomen, more or less ferruginous. The following markings are ivory-white: a transverse spot covering the upper third of the clypeus; upper two-thirds of the inner orbits, including the ocular sinus and extending to opposite the posterior ocelli; upper half of the cheeks (broadly separated from the white inner orbits); broad anterior margin of the pronotum (a little produced behind on the sides, but not reaching the mesopleura); a small triangular spot in the hind corner of the pronotum, close to the tegula; a median, rectangular spot in the posterior third of the mesonotum (between the parapsidal furrows); a line on each side of the mesonotum, close to the tegula; scutellum (except for the apical, depressed rim and a broad, semicircular, basal spot); entire upper plate of the mesepisternum; dorsal lateral areas of the propodeum, covering the lateral angles and extending slightly into the concavity and over the ventral areas; tegulæ anteriorly, posteriorly and along the inner margin; apical margins of the first to fifth abdominal tergites, the fasciæ deeply emarginate on each side of the middle (on the fourth and fifth tergites the median portion is nearly as wide as the sides, but it is considerably narrower than the sides on the second and third, while the first is but narrowly margined with white in the middle and has the sides abruptly and very extensively white); a small spot in the hind angles of the third to fifth sternites; an elongate, narrow spot on the anterior (outer) face of the middle and hind coxæ; outer apices of all the femora; a stripe on the outer face in the basal half of the front tibix; and outer face of middle and hind tibiæ. The under side of the sixth to tenth antennal segments is more or less spotted with ferruginous to dirty white. Wings subhyaline, fairly uniformly tinged with amberyellow, a little more smoky in the radial cell; veins ferruginous, the costa paler; stigma amber-yellow.

Male unknown.

Peru: Payta, August 28, one female collected by Professor 
T. D. A. Cockerell. Holotype in the Museum of Comparative Zoölogy, at Cambridge.

Microtrimeria finds its nearest relatives in the Neotropical genus Trimeria and the South African Masariella. From Trimeria it differs in the presence of parapsidal furrows, the two apical spurs of the middle tibiæ, the rounded, not mucronate propodeum, and the absence of constriction at the base of the abdominal tergites. From Masariella it may be separated by the rounded, not mucronate nor angular propodeum, the uniformly fusiform flagellum (in the female of Masariella the apical segments are set off as a distinct club), the simple tarsal claws, and the venation (the medio-cubital cross-vein in Masariella ends opposite the submedian vein, or even a little apicad). According to Bradley (1922, Univ. California Publ., Ent., I, No. 9, p. 399), the parapsidal furrows are absent in Masariella, but I find them well developed in the genotype, $M$. alfkeni (du Buysson), as well as in two other species, M. saussurei (Brauns) and M. spinolae (H. de Saussure).

The only other Neotropical genus of Masaridinæ ${ }^{1}$, Ceramiopsis Zavattari, agrees with Microtrimeria in the presence of parapsidal furrows, in the rounded lateral angles of the propodeum, and in the middle tibiæ bearing two apical spurs. It differs conspicuously in the shape of the abdomen (the first segment being narrowed at the base into a neck) and in the mouthparts (maxillary palpi of 6 segments; labial palpi of 4 segments).

I agree with Bradley in placing Masaris saussurei in Masariella. Masaris spinolce (de Saussure), of which I have studied a male and a female, should likewise be transferred to that genus. In both these South African species the scutellum is strongly produced behind, completely hiding the postscutellum when viewed from above, the mesepisternum is completely divided by a suture into an upper and a lower plate (a character also present in Masariella alfkeni), and the parapsidal furrows are well developed. In Masaris vespiformis, on the other hand, the post-

${ }^{1}$ As I have shown in a recent paper (1928, Ann. Mag. Nat. Hist., (10) II, p. 143-145), the genus Paramasaris P. Cameron (Syn.: Zethoides P. Cameron, Plesiozethus P. Cameron, Metazethoides W. A. Schulz) should be removed from the Masaridinae and placed in the subfamily Gayellinae. 
scutellum projects considerably behind the scutellum, the mesepisternum is not divided by a suture, and the parapsidal furrows are absent. Since, according to Brauns, Masaris discrepans Brauns is exceedingly close to $M$. saussurei Brauns, there can be little doubt that all South African species thus far placed in Masaris are more correctly placed in Masariella, as was suspected by Bradley.

Having had an opportunity to study the female of Trimeria buyssoni Brèthes, I may add a few notes on the generic characters in that sex. I suspect that some of the characters given for the male by Bradley (1922, Univ. California Publ., Ent., I, No. 9, p. 433) are of specific value only. In the female of $T$. buyssoni, the ocelli are placed in a flattened (not in an equilateral) triangle; the antenna consists of 12 segments, the flagellum being uniformly incrassate throughout, without apical club; the parapsidal furrows are absent; the anterior trochanter ends in an obtuse, narrow lobe, which, however, does not project beyond the lower margin of the femur; the anterior femur is swollen and flattened as in the male, but not angled at the base; the middle femur is flattened beneath; both the last tergite and sternite are obtusely pointed at apex, the sternite thickened along the margin and depressed on the disk. I find the larger posterior tibial spur trifid (not bifid as given by Bradley).

Trimeria buyssoni is the only species of Trimeria which I have been able to study. So far as one can judge from the rather incomplete published accounts, the genotype, T. americana $(\mathrm{H}$. de Saussure), and the three other described species, T. neotropica (Mocsáry), T. joergenseni Schrottky, and T. howardi Bertoni, are congeneric with $T$. buyssoni. Of these five species only three appear to be distinct upon morphological characters, viz., $T$. americana, T. buyssoni, and T. neotropica. It would seem that $T$. joergensen $i$ is but a color variant of $T$. buyssoni, while there is nothing in the description of $T$. howardi (apart from differences in coloration) to allow of its separation from T. neotropica. 

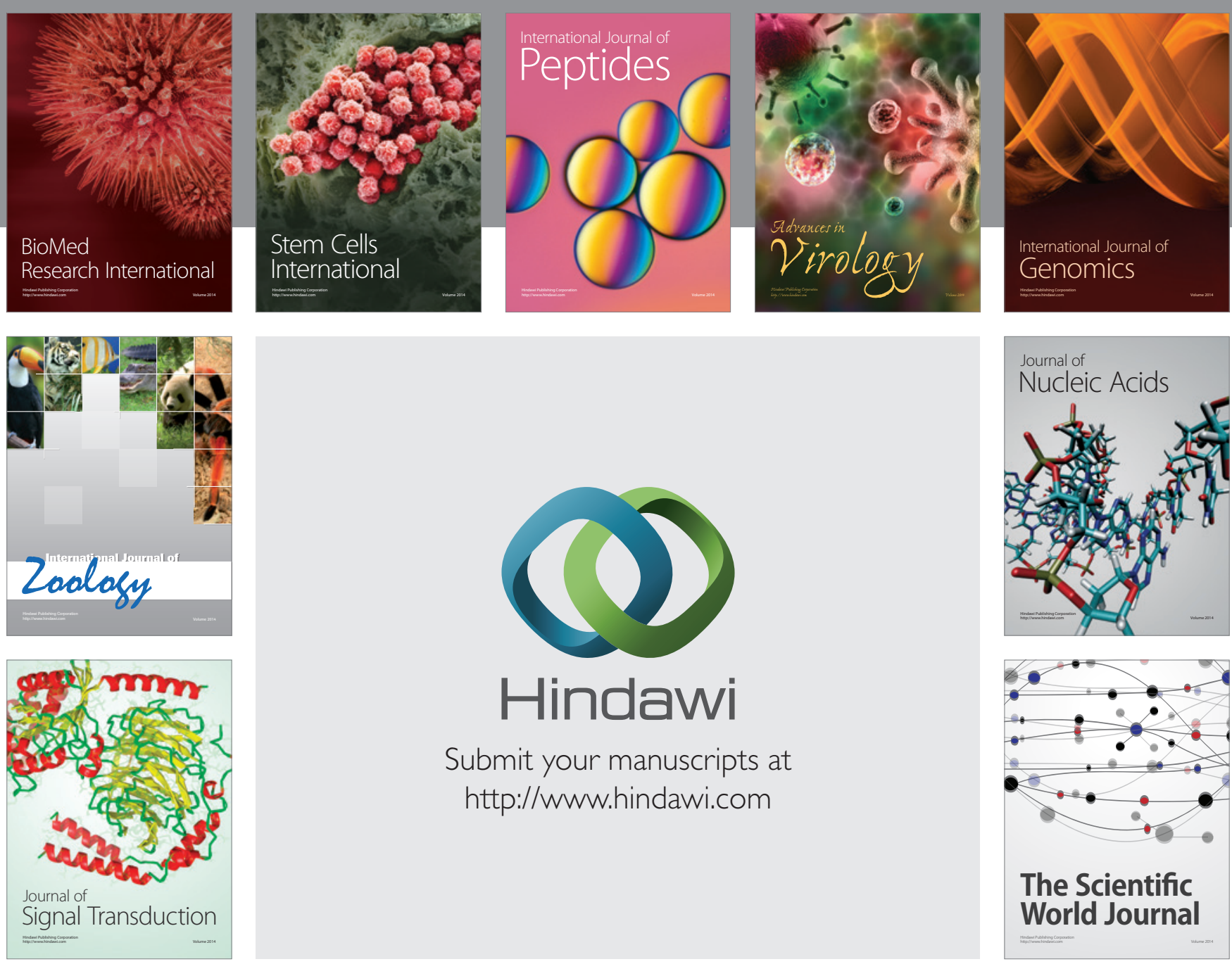

Submit your manuscripts at

http://www.hindawi.com
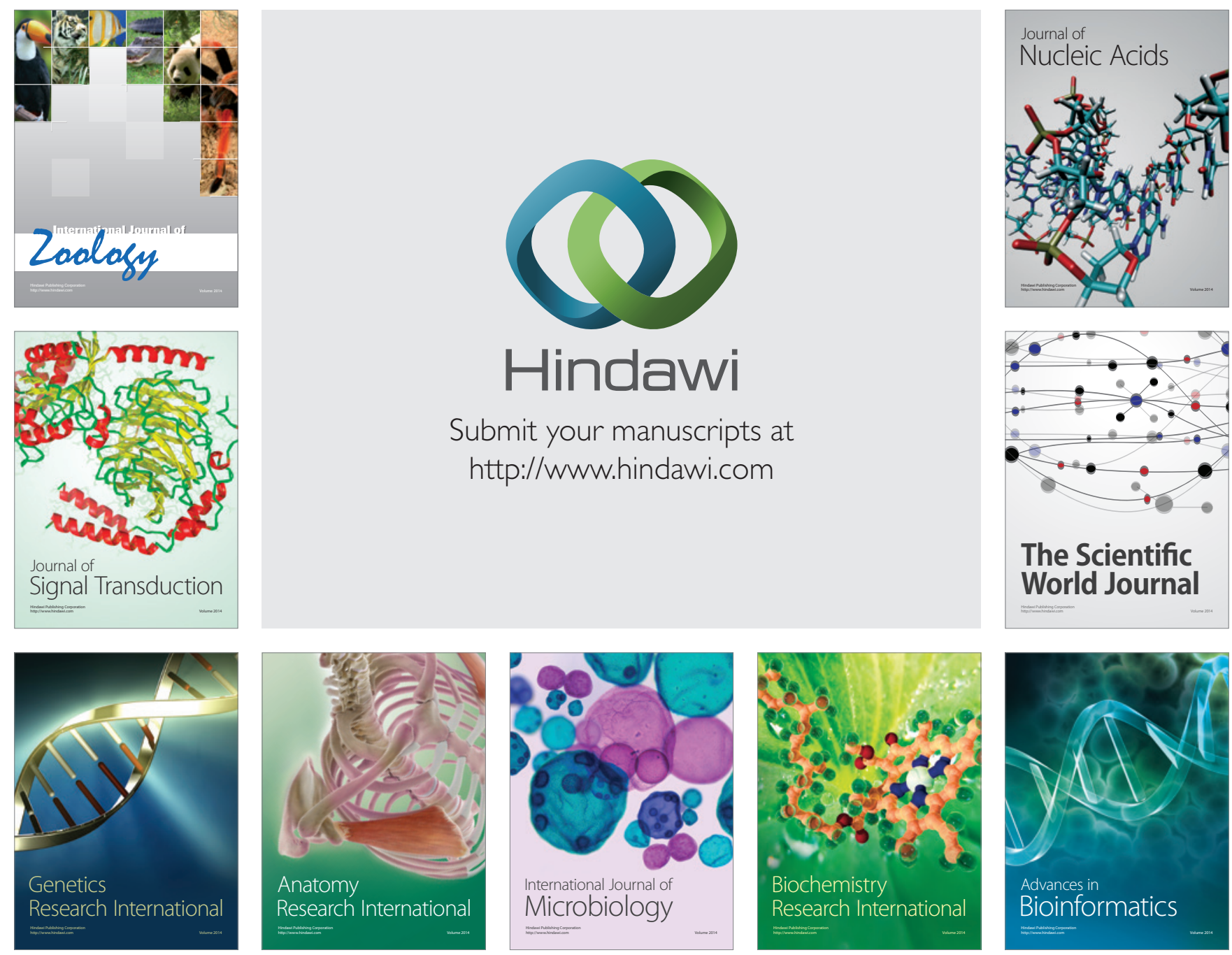

The Scientific World Journal
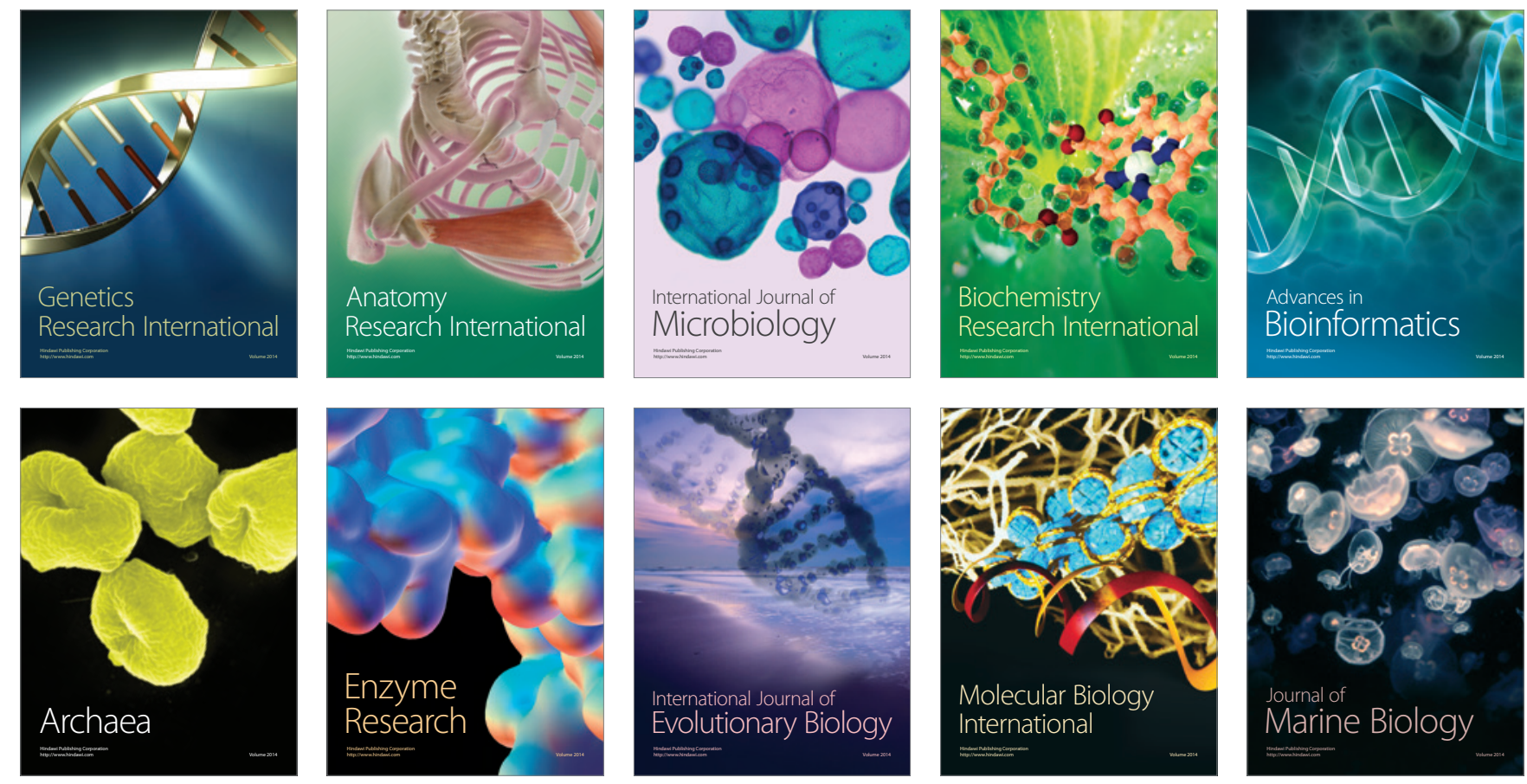